\title{
¡Felicidades! Felicitar como acto de habla
}

María Reyes ${ }^{*}$

\begin{abstract}
Resumen: Este año celebramos el nonagésimo aniversario de nuestro Centro, motivo ante el cual típicamente corresponde hacer una felicitación, como en muchos otros aniversarios. Este artículo es una invitación a detenernos un poco y reflexionar sobre lo que implica hacer una felicitación. Es un acto que, a razón de una potencial causa que le ocurre a nuestro(s) interlocutor(es), nos impulsa a expresarle(s) nuestra alegría. Entre dichas causas está el aniversario de su existencia, ya sea de una persona o de una institución, como es el caso que motiva estas líneas.

Expongo en la primera parte una caracterización sintáctico-semántica y pragmática de este acto de habla; en la segunda, una propuesta de clasificación de las diversas razones que observo por las que felicitamos en México; en la tercera parte presento los resultados de un estudio piloto hecho por medio de un sondeo a estudiantes extranjeros del Centro de Enseñanza para Extranjeros (CEPE) en torno a este acto de habla en su lengua y su cultura.; y en la cuarta parte presento algunas conclusiones y mis felicitaciones a la comunidad del CEPE, razón principal por la que escribí estas líneas.
\end{abstract}

Palabras clave: Actos de habla, condiciones de adecuación, felicitar estudio piloto

\begin{abstract}
This year we celebrate the 90th aniversary of the Centro de Enseñanaza para Extranjeros, which is sufficient reason to congratulate as tipicaly we do in anniversaries. This paper is an invitation to think about all that is implied when we congratulate. It is an speech act done because there is a reason for our hearer to be congratulated. Among those different causes exists the anniversary as a good one, it could be to a person or to an institution, as it is the case in this occasion.
\end{abstract}

\footnotetext{
* Maestra en lingüística aplicada por la unAm, profesora de tiempo completo en el Centro de Enseñanza para Extranjeros (CEPE). Ha impartido clases de español a extranjeros desde 1992. Colaboró en la Escuela de Extensión Canadá durante seis años en la enseñanza del español en el diseño de los cursos, en la elaboración de material didáctico y de exámenes. Ha participado en reuniones académicas nacionales e internacionales. Su área de interés es la pragmática y el Análisis del discurso. En la actualidad es estudiante del doctorado en Lingüística.
} 
On the first part, there is a sintactic, semantic and prgamatic caracterisation of this speech act; on the second part a proposal for tha clasification of the different reasons I observe we congratulate in Mexico; on the third part, the results of pilot study with foreigners students about this speech act in their language and culture. And finally, on the last part I present some conclusions and my own congratulations to the (CEPE) Community, the main reason to write these lines.

Keywords: : Speech acts, conditions of adequacy, congratulations, pilot study. 
MARCO TEÓRICO

\section{El acto de habla}

En sus orígenes, Austin J., (1962), iniciador de la teoría de los actos de habla, planteaba la discusión en torno a la diferencia entre los verbos constatativos y los realizativos, cuya distinción básica es que los primeros describen el mundo y se miden en términos de verdad o falsedad, mientras que los segundos no se pueden medir o determinar con base en las condiciones de verdad, sino que son acciones que al realizarse hacen algo, modifican el mundo, por ejemplo: bautizar, absolver, clasificar, ordenar, suplicar, prometer, preguntar, decir, agradecer, felicitar.

Austin J. (1962) considera que "en circunstancias dadas, en relación a un auditorio determinado, para ciertos fines y con ciertas intenciones, lo que se ha dicho ha sido propio o correcto, como cosa opuesta a incorrecto" (191), es decir, los parámetros ya no son falso-verdadero, sino correcto-incorrecto, lo que posteriormente modificó Searle J. (1962) refiriéndose a adecuado - inadecuado.

Surge entonces el concepto de acto de habla. Cada acto de habla constituye en sí mismo una banda de tres significados: 1. el proposicional, 2. el ilocucionario y 3. el perlocucionario (Austin, 1962; Searle, 1969). El proposicional es el contenido semántico que expresan literalmente las palabras. El ilocucionario es aquél que expresa la intención del hablante al enunciar sus palabras. El perlocucionario es el efecto que los dos anteriores tienen en el destinatario de dicho acto. Esta característica triple del acto verbal remarca la virtud de éste y lo convierte en la unidad básica de la comunicación lingüística (Searle, 1969: 26). Se le conoce también como acto ilocucionario. A partir del surgimiento de este concepto, propuesto por Austin J. (1962) y posteriormente afinado, con su característica antes mencionada, por Searle J. (1969), los estudios en torno a la comunicación entre los hablantes de una misma lengua y los aprendientes de una segunda lengua tomaron como foco de interés todo lo que sucede alrededor de la comunicación, ampliando así la visión de la lengua desde la morfosintaxis y la semántica hasta ubicarla en una dimensión interactiva. Entre las enormes aportaciones y claridades que nos ofrece Austin J. (1962) con su teoría de los actos de habla, en estas líneas sólo resalto el señalamiento de que un acto de habla tiene una repercusión directa respecto a lo que el interlocutor va a pensar, sentir, creer o hacer, es decir, que la mayoría de los actos de habla demandan una acción por parte de su(s) destinatario(s).

Searle J. (1976) propone una clasificación de los actos de habla en cinco grupos: 1. Asertivos, con los que decimos cómo son las cosas. 2. Directivos, con los que tratamos que los otros hagan cosas. 3. Compromisivos, con los que nos com- 
prometemos a hacer cosas. 4. Expresivos, con los que expresamos nuestros sentimientos y actitudes, y 5 . Declarativos, con los que producimos cambios a través de nuestras emisiones.

El acto de felicitar es un acto expresivo, junto con actos como agradecer, disculparse, hacer un cumplido, dar la bienvenida, dar el pésame, lamentar, etc. La gran mayoría de estos actos "especifican una reacción del hablante ante una situación en la que el oyente toma parte activa o pasiva" (Havertake, 1994: 80). Son, asimismo, actos reactivos ante un cambio en el mundo del interlocutor (82). Lo que el autor afirma al respecto es que cuando un hablante desatiende esta circunstancia de su interlocutor conlleva la implicación de ser un hablante socialmente incompetente (produce actos de habla inadecuados). Por su parte, Verschueren (1981) afirma que "un rasgo distintivo de los actos expresivos no es la expresión de un estado psicológico como tal, sino la de un estado psicológico importante para el oyente". (81) Esto nos lleva al hecho de que los actos de habla se enuncian con base a ciertas reglas, afirmación que plantea Searle J. (1969) en su teoría. Este autor desarrolla su teoría con base en la hipótesis de que hablar un lenguaje "es tomar parte en una forma de conducta gobernada por reglas" (Searle, 1969: 25) misma que a lo largo de su libro se transforma en la hipótesis de que "hablar un lenguaje consiste en realizar actos de habla" que, en general son posibles debido a que "se realizan de acuerdo a ciertas reglas para el uso de los elementos lingüísticos". (26)

Searle J. (1969) establece que un acto ilocucionario requiere de ciertas condiciones necesarias y suficientes para que éste sea realizado con éxito. Estas condiciones son un conjunto de proposiciones que dentro de sí mismas entrañan lo que hace que un acto, en los hechos, lo sea; y a su vez, cuando un hablante hace un determinado acto implica que en los hechos conjunta esas condiciones. De tal manera que cada condición es necesaria para la realización del acto y el conjunto de condiciones es, al mismo tiempo, suficiente para que el acto ocurra. Las reglas que conforman un acto de habla son cuatro necesarias y suficientes: 1 . de contenido proposicional, 2. preparatoria, 3. de sinceridad y 4. esencial; Ilamadas condiciones o reglas de adecuación. La producción de una instancia (u oración) bajo esas condiciones constituye un acto de habla, que es la unidad básica de comunicación lingüística.

Con base en lo anterior es pertinente especificar las reglas de adecuación del acto de habla "felicitar". Searle (1969) toma el acto de "prometer" para desarrollar sus planteamientos, sin embargo, menciona algunos otros actos, entre los cuales se encuentra el de felicitar, cuyas reglas de adecuación son las siguientes (875): 
Contenido proposicional:

Regla preparatoria:

Regla de sinceridad:

Regla esencial:
Algún evento, acto. E relacionado con $\mathrm{O}$. $\mathrm{E}$ es de interés para $\mathrm{O}$ y $\mathrm{H}$ cree que $\mathrm{E}$ es de interés para $O$.

$\mathrm{H}$ se alegra de que $\mathrm{E}$ sea el caso.

Cuenta como una de expresión de alegría por $\mathrm{E}$.

(Nota: $\mathrm{O}=$ oyente, $\mathrm{H}=$ hablante, $\mathrm{E}=$ algún evento)

Como lo observamos y como lo afirma Searle (1969), el acto de "felicitar es una expresión de su regla de sinceridad". (75)

\section{Sintaxis y semántica}

Desde el punto de vista sintáctico, podemos decir que felicitar es un verbo regular que se construye con un complemento directo y, si es el caso, un adjunto. Es un verbo con dos argumentos y un adjunto opcional de acuerdo con la situación de comunicación. Uno de los argumentos es el sujeto y el otro es quien recibe la felicitación. Así, tenemos: Pedro felicitó a su hermano. Si dentro del contexto es necesario aclarar más, agregamos más información, es lo que comprende el adjunto; éste generalmente expresa la causa, va introducido por la preposición "por" seguida de un sintagma verbal o nominal, pero también puede ser de tiempo o de lugar. Tenemos Pedro felicitó a su hermano por su cumpleaños / el día de su cumpleaños/ en la alberca. Asimismo, en caso de hacer la felicitación directamente a alguien, la oración puede reducirse a: Te felicito en cuyo caso el pronombre de complemento directo Te es uno de los argumentos, el otro está en la flexión verbal; puede ser el caso de que ningún adjunto sea necesario en la comunicación ya que si el contexto de enunciación aclara la causa de la felicitación, ésta puede omitirse y el acto se cumple. Algo que sucede con este verbo, en casos como: te, lo - la (a ud.), los - las (a uds. ) felicito / felicitamos, es que la misma fuerza ilocucionaria se puede comunicar bajo a la expresión: felicidades, lo cual de hecho es muy común.

En cuanto al aspecto léxico del verbo se trata de una "realización" dado que la acción de felicitar llega a su término cuando se realiza, no se felicita en partes o a través de un proceso. De los rasgos que distinguen el aspecto léxico de los verbos, felicitar cumple ser durativo, delimitado y dinámico.

Por otra parte, en ADESSE (Alternancias de Diátesis y Esquemas Sintáctico-Semánticos del Español), una base de datos con "el análisis sintáctico-semántico de un corpus que permite ofrecer para cada verbo una completa caracterización sintáctico-semántica", este verbo es caracterizado como una valoración, la cual está definida como 
"Una entidad dotada de capacidad comunicativa y de conciencia (A1) valora verbalmente una entidad o un hecho (A2) por alguna razón o con algún argumento (A3). Es decir, una persona expresa una felicitación a otra por alguna razón.

\section{Interacción}

A nivel de la interacción verbal, los actos expresivos sirven para resaltar el componente social de ésta. Felicitar, como los otros actos expresivos, es un medio por el cual los interactantes establecen su relación con el otro. Dumitrescu D. (2004), en su artículo sobre el acto lingüístico: desear(le algo a alguien), afirma que el deseo cumple una función relacional al igual que los cumplidos, yo agrego que también la felicitación, representando una especie de "regalo verbal". Afirma del deseo que "constituye un poderoso marcador ritual de solidaridad entre los miembros de un grupo social, quienes al emplearlo reafirman su pertenencia a la misma comunidad discursiva y su adhesión al mismo sistema de valores éticos y de códigos de conducta" (267). Me parece que esta caracterización sobre desear da cabida al acto de felicitar. No sólo eso sino que se presentan algunos casos en los que desear y felicitar se intersectan en la enunciación. Son tres casos muy concretos de la realidad social que Dimitrescu (268) ofrece como ejemplos de la expresión de buenos deseos (en los que buenos deseos es desear felicidad por el evento); y que yo distingo para fines de este trabajo que son también expresiones de felicitación, me refiero a: feliz cumpleaños, feliz Navidad, feliz Año Nuevo. Ciertamente, son buenos deseos situacionales cuyas fórmulas lingüísticas son fijas y que se usan en estas celebraciones colectivas (Navidad y Año Nuevo) y eventos individuales (cumpleaños) que ocasionan alegría. Es decir, tanto para desear como para felicitar usamos las mismas expresiones cuando es Navidad, cuando es Año Nuevo y cuando alguien cumple años. En este último caso esto sucede únicamente cuando decimos: feliz cumpleaños. Si decimos que cumplas muchos años más, expresamos buenos deseos, pero no felicitamos. (por la Regla de sinceridad). Para ejemplificar más lo anterior pensemos en el caso del día de la boda: para felicitar, generalmente, vamos a decir: „felicidades!, en cambio, si queremos expresar nuestros buenos deseos vamos a decir algo como: iqué sean muy felices! en cuyo caso se expresa el deseo de que en el futuro los recién casados sean felices, que vivan contentos, no es propiamente una felicitación por el evento de la boda. En los dos ejemplos anteriores ambos actos proposicionales están claramente diferenciados.

Felicitar es un acto que, presumo, se realiza en muchas culturas y lenguas, y sin embargo, más allá de (mis) observaciones intuitivas, no sabemos bien a bien cómo se hace en la sociedad mexicana, ni cuáles de sus rasgos son universales y cuáles son culturalmente dependientes. Muchas veces, huecos como éste en 
nuestro conocimiento dificulta nuestros esfuerzos por abarcar el componente pragmático en la enseñanza del español a extranjeros.

Considerando el acto de felicitar desde la perspectiva de las rutinas conversacionales, vemos que conlleva un alto grado de expresión formulaica. Frente a actos como mentir, por ejemplo, que requiere de una elaboración del contenido proposicional, las expresiones para felicitar se limitan a: felicidades, feliz aniversario, feliz cumpleaños, enhorabuena, te felicito por..... sin embargo, su omisión o fallo muy probablemente nos lleve a pensar en una potencial tensión en las relaciones interpersonales (Verschueren, 1981: 134), o en un desconocimiento de la competencia comunicativa. Hoy sabemos que en la realización de actos de habla específicos intervienen elementos sociolingüísticos propios de la comunidad de habla en la que éstos tienen lugar. De hecho, una gran parte de los actos de habla sólo pueden realizarse en sociedades que posean los marcos institucionales que estos requieren (Sperber y Wilson, 1995: 240 y ss). Los elementos contextuales en torno al acto de felicitar propios de la comunidad mexicana no han sido estudiados. En la siguiente sección presento una primera aproximación a los mismos.

\section{PROPUESTA}

\section{Situaciones de uso de "Felicitar"}

Respecto a los contextos en los que expresamos felicitaciones, lo que observo en el habla de la comunidad mexicana que me circunda es que hay una clara división en dos: a) aquéllas acciones que requieren un esfuerzo de parte del individuo que recibirá la felicitación, las llamaremos Realización; y b) aquéllas que no conllevan ningún esfuerzo (al menos de forma evidente) como lo son los eventos relacionados con el pasar del tiempo, que llamaremos Estado. Se podría decir que en los eventos que pertenecen al grupo Realización la participación del receptor de la felicitación es activa, mientras que para los que no realizan un esfuerzo, Estado, su participación para que ésta suceda es pasiva.

La clasificación anterior comprende a su vez diferentes razones que a los mexicanos nos llevan a expresar una felicitación, se conforma de la siguiente manera:

\section{Estado}

1. Tiempo: Aniversarios

Cumpleaños, Navidad, Año Nuevo, fiesta nacional, aniversario matrimonial, laboral, Día de la madre, Día del padre, etcétera.

2. Azar: Juegos de azar

Juegos de azar con baraja, dados, fichas, máquinas, lotería 
3. Parentesco: Mostrar fotografías de la familia

Tener hijos o familiares y mostrar fotografías de ellos

Realización

1. Medio académico

Lograr algo como buenas calificaciones, premio escolar, graduación, etcétera.

2. Medio deportivo

Lograr algo como una medalla, triunfo, esfuerzo, mejora, entre otros.

3. Medio laboral

Obtener de un nuevo empleo, ascenso, reconocimiento, jubilación, etcétera.

4. Evento de vida

Tener un hijo, un nieto, casarse, primera comunión o equivalente, divorciarse, entre otros.

5. Salud

Recuperar la salud o la figura.

6. Imagen

Verse bien con una ropa o un peinado.

7. Valor

Vencer el miedo que da hacer algo.

8. Compras

Comprar una casa, una computadora.

9. Aptitud

Poseer un don artístico, social, profesional, manual, gastronómico, etcétera.

Dentro de los eventos incluidos en Estado, vemos que el factor tiempo tiene una estrecha relación con el acto de felicitar. En la mayoría de los casos, si no es que en todos, la participación de quien recibe la felicitación es pasiva. No hacemos nada para cumplir años, ni para que la Navidad y el Año Nuevo ocurran. Los eventos cumpleaños y Año Nuevo son motivo de felicitación en un amplio número de lenguas y culturas, como lo veremos en los resultados. Igualmente, en el terreno de los juegos de azar, en los que no depende de nosotros tener éxito. Si una persona se gana un premio grande, o en el caso más afortunado, el premio mayor de la lotería, le expresamos una felicitación. Creo que felicitamos su buena suerte y el cambio positivo que tendrá en su vida dicha ganancia. Sin embargo, si gana un poco de dinero en un juego con amistades o en un casino, la felicitación no siempre ocurre. Por último, tenemos que en ocasiones felicitamos (o nos vemos forzados a hacerlo) a quien nos muestra fotografías de sus hijos, concretamente, de un bebé. Es una felicitación que la persona recibe por el hecho de haber teni- 
do un hijo o hija, pero no me estoy refiriendo en este punto al hecho de haberlo tenido sino de que muestra una fotografía, podemos escuchar algo como: " $i A h$ ¿Es tu bebé? Se parece a su ..... o te felicito, está muy bonito!

Los puntos del 1 al 7 de los eventos correspondiente a Realización muestran de manera evidente la razón para la felicitación, no es necesario profundizar más los comentarios. Comentaré únicamente los puntos 8 y 9 .

En relación con el punto 8 . Compras. Creo que felicitamos cuando se trata de la compra de algo que modifica en buena medida la vida de una persona de forma positiva, o que implica un gran esfuerzo. Construir o comprar una casa representa de alguna manera ambas cosas. Esto explica la razón de haber puesto en el cuestionario dos preguntas, una de ellas pregunta si felicitas a alguien cuando te dice que se compró una casa, y la otra, si te dice que se compró una computadora. La compra de esas dos cosas es diferente en términos de cómo modifica la vida del individuo. Comprar una computadora, no es razón suficiente para expresar una felicitación. Creo que cuando se trata de algo con lo que ya se está familiarizado no decimos felicidades salvo un caso particular en el que dicha acción implique un esfuerzo especial para quien lo ha realizado, pero en general ya es algo con lo que se vive en la actualidad, al menos en cierto medio social en México y para totalidad de los estudiantes extranjeros del CEPE. Es decir, entre ellos nadie expresa una felicitación a causa de la compra de una computadora (como se verá más adelante). Por el contrario, al realizar la compra de una casa, de forma general tendemos a expresar felicitaciones, tanto en México como en otros países, como lo muestran los parciales resultados de este estudio.

En cuanto al punto 9. Aptitud, cuando alguien sobresale públicamente por algún logro, cuando recibe un reconocimiento por alguna virtud o cuando alguien ejerce alguna habilidad artística, cualquiera que ésta sea y muestra su obra, creo que la tendencia general es a felicitar a la persona. Si, además, la obra de arte es de nuestro agrado, sin duda vamos a expresar nuestra felicitación al artista. (Véase apartado Resultados). Puede ser que la obra no nos guste, pero la felicitación existe; aunque también sucede, sin duda, que hay críticos de arte, especialistas en el tema, personas con un nivel alto de exigencia a la propia satisfacción artística o estados anímicos personales que no favorecen la expresión de la felicitación y entonces ésta no sucede. (Véase apartado Resultados). Un espacio muy institucional para expresar nuestra felicitación, entre otros actos como opinar, halagar, quejarse, se encuentra en los cuadernos que se colocan en las exposiciones de pintura, escultura, fotografía, grabado, en el teatro, en la música. En resumen, la expresión artística es argumento para expresar una felicitación. 
ESTUDIO PILOTO

\section{Muestra e instrumento}

Lo primero que es necesario decir es que el cuestionario elaborado y aplicado a 42 estudiantes extranjeros del CEPE tiene la calidad de un estudio piloto, requiere de una reconsideración de los resultados, de revisiones y posteriores modificaciones para poder afirmar con mayor seguridad las diferencias y similitudes en torno al acto de felicitar entre las diferentes lenguas y culturas. Presento en esta sección sólo algunos de los resultados que considero que dan un poco de luz y que merecen ser mencionados y revisados en estudios posteriores sobre este tema.

El tamaño de la muestra es de 42 estudiantes extranjeros de los niveles Intermedio 1, 2, 3 y Superior del Centro de Enseñanza para Extranjeros. Con la siguiente distribución de países:

\begin{tabular}{c|l}
$\begin{array}{c}\text { Número de } \\
\text { estudiantes }\end{array}$ & \multicolumn{2}{|c}{ País } \\
\hline 18 & Japón \\
\hline 5 & Corea del Sur \\
\hline 3 & Estados Unidos \\
\hline 3 & Australia \\
\hline 3 & Haití \\
\hline 1 & Taiwán \\
\hline & $\begin{array}{l}\text { Francia, Suecia, Rep. del Congo, } \\
\text { Alemania }\end{array}$
\end{tabular}

Dado que la población de los diferentes países es muy baja (de 5 a 1), menor que la mitad de Japón (9), mencionaré solamente los casos en que los que la respuesta por parte de todos los estudiantes de la muestra fue un Sí y un NO en el 100 por cierto de las respuestas. Y para extender un poco los comentarios, posteriormente, me concretaré a las respuestas de la población japonesa considerando que las respuestas de 18 estudiantes pueden dar algunos indicios más confiables de la reacción en torno al acto de felicitar que los que solamente están representadas por un estudiante.

El instrumento. La instrucción para el estudiante es: Si nos ubicamos en lo que es usual en tu país, ¿en situaciones normales felicitas a alguien... en su cumpleaños?... si gana un premio escolar? Se enlistan 24 preguntas cuya respuesta solo puede 
ser Sí - NO; asimismo, hay 6 preguntas en formato de respuesta abierta. Son 30 preguntas en total. Con "condiciones normales" me refiero únicamente a que la persona que supongan no sea alguien con quien hayan tenido un problema en particular. La idea es que expresen lo que consideran que es más frecuente en su país, pero al mismo tiempo desde su propia experiencia.

Las 24 preguntas cerradas contienen la temática de las causas Sin esfuerzo/ Con esfuerzo propuesto en el punto anterior. Las seis preguntas abiertas se refieren a si en su país se celebran los aniversarios de las instituciones (pregunta 2.); a quién se felicita en esos casos (pregunta 3); si conocen otras expresiones además de "felicidades" en español (pregunta 4); si en su lengua usan la misma expresión para felicitar a alguien en su cumpleaños y al ganar el primer lugar en matemáticas (pregunta 5). Finalmente, la pregunta 6 es ¿Qué pasaría si las personas no se felicitaran? (Véase el cuestionario completo en el anexo)

\section{Resultados}

Las preguntas que recibieron en un 100 por ciento la respuesta afirmativa fueron: La pregunta 1. ¿Felicitas a alguien en su cumpleaños?, la pregunta 5. ¿Felicitas a alguien el día de su boda? y la 19. ¿Felicitas a alguien por motivo del Año Nuevo? Todos los estudiantes de los 14 diferentes países contestaron que sí a las tres.

De esas tres preguntas la 1 y la 19 se relacionan con el tiempo, uno de forma individual: el cumpleaños, y otro de carácter social: el inicio de un nuevo año. La 5 tiene que ver con un evento en la vida. De manera intuitiva, con base en la información que comparto como ciudadana de esta sociedad, afirmo que los mexicanos también felicitamos en esa tres ocasiones. Con lo anterior podríamos aseverar que en 15 países, incluido México, las personas se felicitan cuando cumplen años, en el Año Nuevo y el día de su boda.

Las preguntas que recibieron en un 100 por ciento la respuesta negativa fueron: La pregunta 8 ¿Felicitas a alguien si se compra una computadora? y la 18 ¿Felicitas a alguien si te dice que se va a divorciar?

Comprar una computadora no es motivo de felicitación en ninguno de los países de la muestra, lo cual me hace reiterar lo mencionado anteriormente en el sentido de que comprar algo que no va a representar un cambio significativo en la vida cotidiana no es motivo de felicitación. En esos países es común tener una computadora. Probablemente en el caso de los mexicanos la respuesta negativa no sería tan contundente.

Para el caso de la pregunta 18, es evidente que el divorcio no es un evento feliz y que, si bien en la actualidad ha subido su índice, no parece motivo de felicitación a pesar de que pueda, en ocasiones, representar una mejor situación futura; el implícito del malestar emocional y general que conlleva ha de ser suficiente para 
apagar una posible felicitación. Habría que investigar más las razones. Creo que en México sería el mismo caso.

Después de las respuestas homogéneas, menciono ahora las respuestas exclusivamente de los estudiantes japoneses. El siguiente número de respuestas negativas lo tiene la pregunta 9 ¿Felicitas a alguien el día de fiesta nacional? con un total de 14, o sea que 4 sí felicitan a alguien ese día, 14, no.

Después de la anterior, cuatro preguntas reciben 12 respuestas negativas, éstas son:

12. ¿Felicitas a alguien si gana en un juego de azar en un casino?

20. ¿Felicitas a alguien si es artista y presenta su obra, pero a ti no te gusta?

21. ¿Felicitas a alguien si te muestra las fotos de sus hijos?;

22. ¿Felicitas a alguien si se atrevió a hacer algo que le daba miedo?

Las preguntas 12 y 21 pertenecen al grupo Estado. Ganar algo en un juego de azar en un casino o con amigos y mostrar la foto de un familiar son actividades que para 12 de 18 estudiantes no merecen felicitación. En el caso de la pregunta 20. debo mencionar antes que existe la pregunta 11 que dice: ¿Felicitas a alguien si es artista y presenta su obra?. Al comparar las dos preguntas vemos que las respuestas negativas para la 11 son 5 , mientras que para la 20 son 12 , lo que nos dice que además de esos cinco existen otras siete personas que no felicitan si no les gusta la obra. Habrá que confirmar este resultado del sondeo con una muestra más grande para poder afirmar algo sobre la sinceridad y solidaridad de los miembros de la cultura japonesa con respecto a un artista en la presentación de su obra.

La pregunta 3 ¿Felicitas a alguien cuando se ve bien con alguna ropa o peinado? Obtiene 11 respuestas negativas ( 6 hombres, 5 mujeres), lo cual puede querer decir que el esfuerzo que hace alguien para verse bien ya sea por su ropa o por su peinado es reconocido por medio de una felicitación en 7 de los 18 estudiantes.

De las preguntas que obtuvieron muchas respuestas positivas, se encuentran las siguientes: 14. ¿Felicitas a alguien si gana una medalla en algún deporte? De los 18 estudiantes 17 contestaron que sí; la pregunta 7. ¿Felicitas a alguien si ascendió en su trabajo? De los 18 estudiantes 16 contestaron que sí; 15 estudiantes respondieron que sí a las siguientes tres preguntas: 4. ¿Felicitas a alguien si recuperó su salud o su figura?; 13. ¿Felicitas a alguien si te dice que va a tener un hijo?; 15. ¿Felicitas a alguien si cumple otro año más (de matrimonio, con su novia, de jefe, etc.). Me parece que las respuestas de los 18 estudiantes japoneses se acercan a las respuestas que darían hablantes nativos del español mexicano. Con esto quiero decir que las actividades: ganar una medalla, ascender en el trabajo, recuperar la salud, tener un hijo y cumplir un aniversario más, son razones suficientes para expresar una felicitación tanto para personas japonesas como mexicanas. Sin embargo, es necesario probarlo con una muestra más grande. 
Me despierta especial interés la pregunta 24 debido a que es una pregunta sobre la reacción que se espera del interlocutor que recibe la felicitación. De los 18 estudiantes japoneses 14 contestaron que sí esperan que la persona les diga: Gracias. Me parece que en México la gran mayoría de las personas esperamos el agradecimiento después de una felicitación, pero es necesario probarlo.

Entre las preguntas de respuestas abiertas, la que obtiene una respuesta homogénea es la 5. ¿En tu lengua materna, si una persona cumple años y otra persona gana el primer lugar en matemáticas, usas la misma expresión para felicitarlas? La respuesta de todos es sí, lo que quiere decir que el japonés y el español comparten esa característica: usan la misma expresión para un acto cuyo motivo es una fecha particular, como es el cumpleaños y cuando hay implícito un esfuerzo como es el caso de obtener el primer lugar en matemáticas. No es el caso del inglés, francés, turco, finlandés, noruego, alemán y chino los cuales tienen dos expresiones diferentes para los dos eventos.

\section{CONCLUSIONES}

Con base en este estudio piloto, el acto de felicitar no parece ser muy diferente entre las diferentes culturas y lenguas representadas por los estudiantes del CEPE. Sin embargo, para poderlo afirmar con mayor seguridad es preciso realizar un estudio con una muestra más representativa.

La totalidad de los estudiantes (42) de los 14 países pertenecientes a la muestra de este primer sondeo señalan usar la felicitación cuando su interlocutor cumple años, cuando es su boda y cuando es Año Nuevo, ocasiones en las que también felicitamos en México.

Retomando la idea de que felicitar es un "regalo verbal" parece viable lanzar la hipótesis de que felicitar es un regalo que sí se otorga en la cultura japonesa dado que hay muchas preguntas con respuesta afirmativa, y que es pertinente probar la misma hipótesis en las diferentes culturas de los estudiantes que pasan por las aulas del CEPE. De esta manera tendremos una aproximación más clara de lo que es universal de este acto y de lo que está culturalmente determinado.

En relación a las causas de la felicitación, me parece que la división en los grupos Estado/Realización es una buena aproximación para conocer las condiciones que favorecen la producción de este acto en las diferentes culturas, sin que eso quiera decir que no se pueda mejorar. Por último, es importante aclarar que no estoy reportando aquí muchas de las respuestas obtenidas a partir de la aplicación del cuestionario. Quedan pendientes para la continuación de este estudio. 


\section{Felicitación}

Después de las líneas anteriores sólo me queda expresar mi felicitación a todos los trabajadores del Centro de Enseñanza para Extranjeros, esa comunidad de trabajo que se encarga de la enseñanza de la lengua y la cultura con las se expresan una buena parte de los mexicanos. Es una institución que se caracteriza por recibir a quienes más allá de las fronteras deciden acortar la distancia tanto geográfica como cultural y se animan a venir o son traídos por alguna determinada circunstancia, y aceptan lo que la unAm por medio del CEPE les ofrece. Es un Centro que, no sin los problemas naturales, funciona haciendo lo que hace con sus diferentes departamentos que lo componen. Es un lugar donde el ritmo está determinado por los cursos que se ofrecen (acordes con la población estudiantil que lo conforma), como sucede en cualquier escuela, pero con un tinte que lo distingue: sus estudiantes —un conjunto de estudiantes extranjeros originarios de una enorme diversidad de países, de lenguas y de historias personales además de la heterogénea comunidad mexicana que aprovecha los cursos de cultura y los de formación de profesores en la enseñanza de español. Así, trabajadores y estudiantes pertenecemos a un lugar que nos distingue y al que distinguimos. Me atrevo afirmar que un alto porcentaje de su personal está orgulloso de que su lugar de trabajo sea este Centro nonagenario. En un sano ejercicio, este aniversario podría ser una buena ocasión para, como lo hace una persona, revisar su estado de salud, atender el diagnóstico obtenido y de esa forma apostar por unos años venideros con el espíritu de ser y hacer mejor, de ofrecer lo mismo, pero de mejor manera, igual que como lo hace una persona que aprecia su vida y su trabajo.

¡Felicidades! a todos los que de aquí somos temporal o permanentemente. 
REFERENCIAS

Austin, J. L. (1962) How to do things with Word. Oxford: Oxford University Press. (1962) Cómo hacer cosas con palabras: palabras y acciones. Barcelona: Paidós.

BASE DE DATOS ADESSE (Alternancias de Diátesis y Esquemas Sintáctico-Semánticos del Español) http://adesse.uvigo.es/

Dumitrescu, D. (2004) La expresión de buenos deseos hacia nuestro prójimo: ¿un acto de habla cortés automático? Bravo D. \& Briz A. (eds.). Pragmática sociocultural. Estudios sobre el discurso de cortesía en español. Barcelona: EDICE y Ariel, pp. 265-283.

HAVERTAKe, H. (1994) La cortesía verbal. Estudio pragmalinguistico. Madrid: Gredos.

Real Academia Española, Asociación de Academias de la lengua española. (2011) Nueva Gramática de la lengua española. México: Editorial Planeta Mexicana.

Searle, J. (1969) Speech acts-An essay in the philosophy of Language. Cambridge: Cambridge University Press.

__ [1980] (2009) Actos de habla: ensayo de filosofía del lenguaje (7a. ed.). Madrid. Cátedra.

Sperber, D. \& Deirdre, W. (1986) Relevance: Communication and Cognition. Oxford: Blackwell.

__ (1995) La relevancia (2a. ed.)Madrid: Visor.

Rodríguez Ramalle, T.M (2005) Manual de sintaxis del español. Madrid: Castalia Universidad.

VersCHUEREN, J. (1981) The semantics of forgotten routines. Coulmas F.

Conversational routine. Explorations in standardized communication situations and prepatterned speech. La Haya: Mouton, pp. 357-387. 
Anexo 1

\section{UNIVERSIDAD NACIONAL AUTÓNOMA DE MÉXICO CENTRO DE ENSEÑANZA PARA EXTRANJEROS}

Lengua materna

País

Hombre

Nivel

Mujer

Marca tu respuesta

1. Si nos ubicamos en lo que es usual en tu país, ¿en situaciones normales, felicitas a alguien...

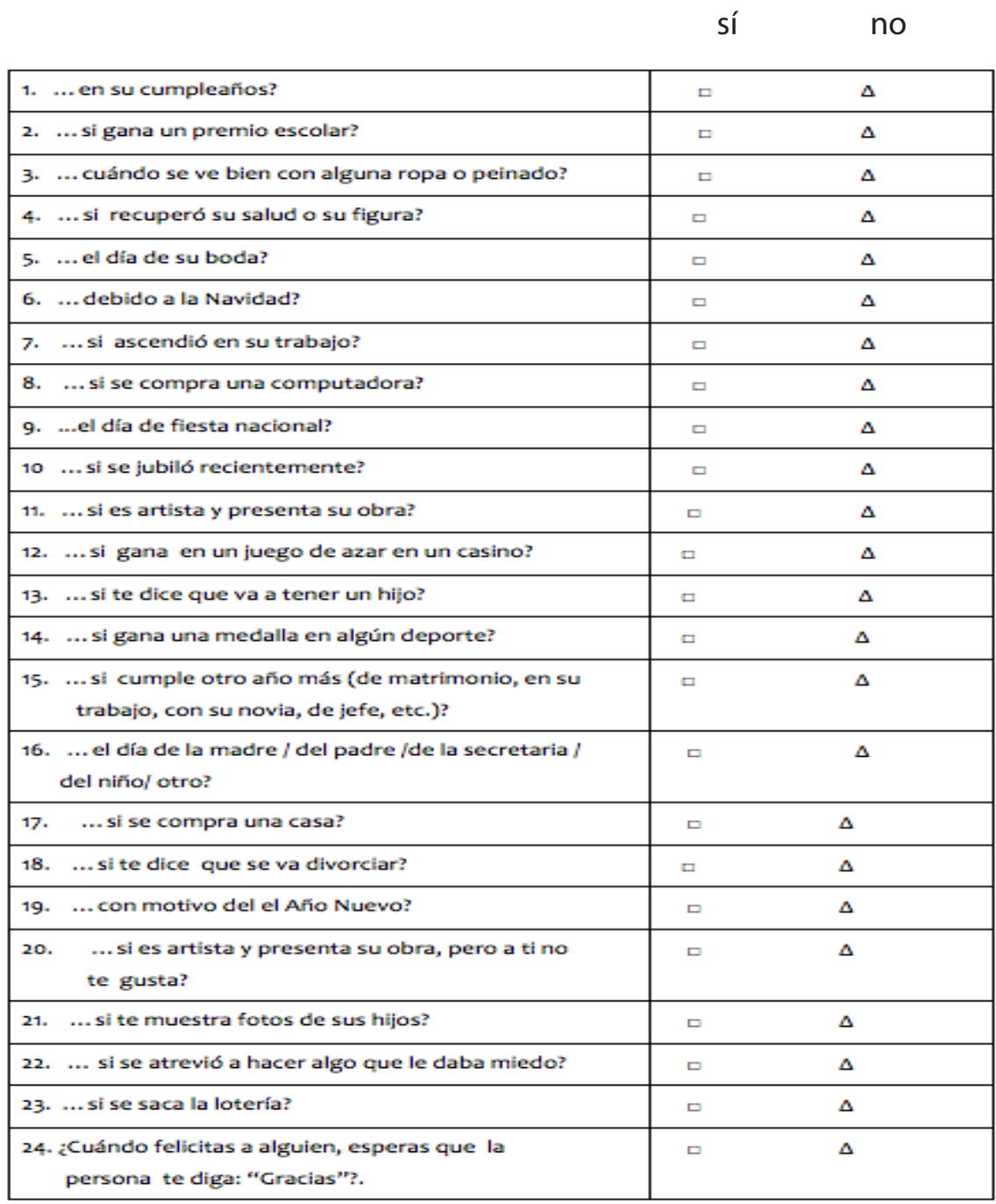


2. ¿En tus país celebran los aniversarios de las instituciones, compañías o empresas?

3. ¿En tu país, a quién se felicita si es el aniversario de una institución?

4. ¿Conoces otras expresiones en español para felicitar además de:"Felicidades"? ¿Cuáles?

5. ¿En tu lengua materna, si una persona cumple años y otra persona gana el primer lugar en matemáticas ¿usas la misma expresión para felicitarlas?

6. ¿Qué pasaría si las personas no se felicitaran? 
